\title{
Presence and molecular characterization of Clostridium difficile and Clostridium perfringens in intestinal compartments of healthy horses
}

Angelika Schoster ${ }^{1,3^{*}}$, Luis Guillermo Arroyo ${ }^{1}$, Henry Rolf Staempfli ${ }^{1}$, Patricia Elisabeth Shewen ${ }^{2}$ and Jeffrey Scott Weese ${ }^{2}$

\begin{abstract}
Background: Clostridium difficile and Clostridium perfringens are commonly associated with colitis in equids, but healthy carriers exist. Scarce information is available on the prevalence of Clostridium spp. in gastrointestinal compartments other than faeces in healthy horses, and it is unknown whether faecal samples are representative of proximal compartments. The objectives were to investigate the prevalence of $C$. difficile and $C$. perfringens in different intestinal compartments of healthy adult horses and to determine whether faecal samples are representative of colonization in proximal sites and overall carrier status.
\end{abstract}

Results: Toxigenic C. difficile was isolated from 14/135 (10.3\%) samples from 8/15 (53.3\%) horses. Between zero and three sites were positive per horse, and multiple sites were positive in four horses. Isolates were recovered from duodenum, jejunum, ileum, right dorsal colon, small colon and rectum. When multiple compartments were positive in a single horse, two different $C$. difficile ribotypes were always present. Clostridium perfringens Type $A\left(C P E, \beta_{2}\right.$ toxin gene negative) was recovered from the left ventral colon of one horse $(0.74 \%, 1 / 135$ samples). Agreement between faeces and overall C. difficile carrier status was good.

Conclusions: Clostridium difficile can be found in different compartments of the gastrointestinal tract of healthy horses, and multiple strains can be present in an individual horse. The prevalence of $C$. perfringens in healthy adult hoses was low, consistent with previous reports. Faecal samples were representative for presence of $C$. difficile in proximal compartments in 5/8 horses (63\%) but were not representative for the specific strain.

Keywords: Clostridium difficile, Clostridium perfringens, Equine gastrointestinal tract, Equine intestinal microflora, Clostridium difficile ribotyping

\section{Background}

Over the past decade Clostridium difficile has emerged as an important enteric pathogen in human [1] and veterinary medicine [2]. Clostridium difficile is an important cause of acute enterocolitis in horses [3-5] with clinical signs ranging from mild self-limiting disease to fulminant necro-haemorrhagic enterocolitis [6]. While clearly a cause of disease in horses, toxigenic strains of $C$. difficile

\footnotetext{
* Correspondence: aschoster@life.ku.dk

'Department of Clinical Studies, Ontario Veterinary College, University of Guelph, Guelph, Canada

${ }^{3}$ Department of Veterinary Disease Biology, University of Copenhagen, Copenhagen, Denmark

Full list of author information is available at the end of the article
}

can also be isolated from faeces of healthy horses, with reported isolation rates of $0 \%$ to $8 \%$ [5,7-9]. While there are numerous point prevalence studies, there has been limited study of colonization of $C$. difficile in different anatomic locations throughout the intestinal tract. Clostridium difficile infection (CDI) is typically associated with colonic disease in horses and humans. More recently CDI has also been connected with small intestinal enteritis in humans [10] and with proximal duodenitis jejunitis in horses [11]. This suggests that C. difficile is also able to colonize the small intestine.

Clostridium perfringens has been associated with enterocolitis in animals, including horses and humans [12,13]. In an earlier study C. perfringens type A has been reported to

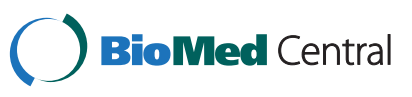


be a normal part of the gastrointestinal flora of healthy horses [14]. Interestingly recent studies have reported low prevalence rates of $0-8 \%$ in faeces of healthy adult horses $[5,13,15-17]$. This organism is mostly associated with colonic disease but has been also identified in the small intestine of horses with gastrointestinal disease [15], in horses with grass sickness and in healthy horses [13]. Nevertheless, clear information about the distribution of C. perfringens in the proximal intestinal tract and information on shedding of this organism over time in healthy horses is lacking.

Faecal samples are commonly being used to test for presence $C$. difficile and C. perfringens; however, disease does not occur in the distal parts of the gastrointestinal system where the faecal microbiota is established, it occurs in proximal components of the intestinal tract. The physiology and local environments of different intestinal tract locations are quite variable and it is logical that the intestinal microbiota is similarly variable. This is important to study because faecal samples are most often used for diagnosis of intestinal tract disease or for epidemiological studies, yet the degree to which they reflect the status of proximal intestinal tract locations is currently unknown.

Therefore, the objectives of this study were to investigate the presence of $C$. difficile and $C$. perfringens in various intestinal compartments of healthy adult horses and to molecularly characterize isolates.

\section{Methods}

Intestinal contents were collected from 15 euthanized horses greater than one year (Table 1) and free of apparent clinical signs of gastrointestinal disease. The horses were euthanized for reasons unrelated to this study. The legal and ethical requirements of the University of Guelph have been met with regards to the humane treatment of animals described in the study.

Within four hours after euthanasia samples were collected from the stomach, duodenum, jejunum, ileum, body of the caecum, right dorsal colon, left ventral colon, small colon and rectum. Samples were collected asepetically via enterotomy and intestinal content was collected using sterile forceps and stored at $-80^{\circ} \mathrm{C}$ until processing.

\section{Clostridium difficile culture}

Two grams of intestinal content or faeces were inoculated into $C$. difficile moxalactam and norfloxacin broth $(\mathrm{CDMN})^{\mathrm{a}}$ and anaerobically incubated at $37^{\circ} \mathrm{C}$ for five to seven days. An aliquot of the broth was alcohol shocked with an equal volume of anhydrous ethanol for one hour. This mixture was centrifuged for ten minutes at $3800 \mathrm{~g}$. The supernatant was discarded and the pellet was streaked onto a CDMN agar plate and
Table 1 Epidemiologic data of horses included in the study

\begin{tabular}{|c|c|c|c|c|c|c|}
\hline Horse & $\#$ & Farm & $\begin{array}{l}\text { Age in } \\
\text { years }\end{array}$ & Gender & Breed & $\begin{array}{l}\text { Reason for } \\
\text { euthanasia }\end{array}$ \\
\hline 1 & \# & $A$ & 3 & $M C$ & Thoroughbred & $\begin{array}{l}\text { Cervical vertebral } \\
\text { malformation }\end{array}$ \\
\hline 2 & & B & 14 & $\mathrm{~F}$ & Welsh Pony & Pulmonary calcification \\
\hline 3 & & C & 4 & $\mathrm{~F}$ & Bashkir Curly & EDM \\
\hline 3 & $\#$ & C & 3 & $\mathrm{~F}$ & Bashkir Curly & EDM \\
\hline 5 & $\#$ & $\mathrm{D}$ & 3 & M & Standardbred & $\begin{array}{l}\text { Cervical vertebral } \\
\text { malformation }\end{array}$ \\
\hline 6 & & C & 3 & $\mathrm{~F}$ & Bashkir Curly & EDM \\
\hline 7 & $\#$ & $C$ & 2 & $M$ & Bashkir Curly & EDM \\
\hline 8 & & C & 4 & $\mathrm{~F}$ & Bashkir Curly & EDM \\
\hline 9 & & $E$ & 3 & $\mathrm{~F}$ & Standardbred & $\begin{array}{l}\text { Cervical vertebral } \\
\text { malformation }\end{array}$ \\
\hline 10 & $\#$ & C & 4 & $M C$ & Bashkir Curly & EDM \\
\hline 11 & \# & $\mathrm{F}$ & 8 & $M C$ & $\begin{array}{l}\text { Irish Sport } \\
\text { Horse }\end{array}$ & Fracture $\mathrm{L} 5$ \\
\hline 12 & \# & G & 3 & $\mathrm{~F}$ & Standardbred & $\begin{array}{l}\text { Cervical vertebral } \\
\text { malformation }\end{array}$ \\
\hline 13 & & $\mathrm{H}$ & 4 & $M C$ & Standardbred & $\begin{array}{l}\text { Cervical vertebral } \\
\text { malformation }\end{array}$ \\
\hline 14 & & I & 3 & $\mathrm{~F}$ & Standardbred & $\begin{array}{l}\text { Cervical vertebral } \\
\text { malformation }\end{array}$ \\
\hline 15 & $\#$ & J & 6 & $M C$ & Hannoverian & $\begin{array}{l}\text { Cervical vertebral } \\
\text { malformation }\end{array}$ \\
\hline
\end{tabular}

\# horses from which C. difficile was isolated from at least 1 compartment $\mathrm{M}=$ male non castrated, $\mathrm{MC}=$ male castrated, $\mathrm{F}=$ female, $\mathrm{EDM}=$ Equine Degenerative Myeloencephalopathy.

anaerobically incubated for 48 hours at $37^{\circ} \mathrm{C}$. Suspicious colonies were subcultured onto blood agar, anaerobically incubated for 24 hours at $37^{\circ} \mathrm{C}$, and confirmed as C. difficile by colony morphology, characteristic odour and production of L-proline aminopeptidase (Pro Disc Remel) $)^{\mathrm{b}}$.

\section{DNA extraction}

DNA was extracted from a pure culture on blood agar with a Chelex resin-based DNA extraction commercial kit (Insta Gene) ${ }^{c}$, using the manufacturer's instructions. The resulting DNA was used as template for subsequent PCR tests.

\section{Ribotyping of $C$. difficile}

A previously described ribotyping method was used to analyse all positive isolates [18]. When the ribotype was a recognized international ribotype previously identified by the PHLS Anaerobic Reference Unit (Cardiff, UK), the appropriate numerical designation (i.e. 078) was used. Otherwise, in-house nomenclature was assigned. 


\section{Toxin gene profiling of $C$. difficile}

PCR detection of genes encoding toxins $\mathrm{A}(t c d A)$ and $\mathrm{B}$ $(t c d B)$ was performed as previously described [19]. The presence of binary toxin (CDT) was tested by amplification of a fragment of the gene $(c d t B)$ [20].

\section{Clostridium perfringens culture}

Two grams of intestinal content or faeces were inoculated into $8 \mathrm{ml}$ brain heart infusion broth $(\mathrm{BHI})^{\mathrm{d}}$ and anaerobically incubated for two days at $37^{\circ} \mathrm{C}$. After incubation an aliquot of the broth was alcohol shocked with an equal volume of anhydrous ethanol for one hour and then centrifuged at $3800 \mathrm{~g}$ for ten minutes. The supernatant was discarded, and the resulting pellet was inoculated onto blood agar and anaerobically incubated at $37^{\circ} \mathrm{C}$ for 48 hours. Clostridium perfringens colonies were identified by colony morphology and double-zone hemolysis. Suspicious colonies were subcultured on blood agar and anaerobically incubated for 48 hours at $37^{\circ} \mathrm{C}$. Christie-Atkins-Munch -Peterson (CAMP) testing was performed on colonies accompanied by a positive control (NTC 3110, NTC 8840).

\section{Clostridium perfringens multiplex PCR}

Typing of $C$. perfringens was based on genes encoding all four major toxins as well as enterotoxin and $\beta_{2}$ as described previously [21].

\section{Statistical analysis}

Kappa values were calculated to compare agreement between positive rectum/faecal samples and overall carrier status of $C$. difficile. Agreement was interpreted as follows: poor agreement $=$ kappa less than 0.20 , fair agreement $=$ kappa 0.20 to 0.40 , moderate agreement $=$ kappa 0.40 to 0.60 , good agreement $=$ kappa 0.60 to 0.80 , very good agreement $=$ kappa 0.80 to 1.00 [22]. The remaining data were analysed in a descriptive manner.

\section{Results}

\section{Epidemiologic data of horses and farms}

Fifteen horses of more than one year were included in the study (Table 1). These horses originated from ten farms, six horses from a single premise and the remaining nine from different farms. Information on diet, housing and administration of drugs including antimicrobials was not available.

\section{Clostridium difficile prevalence}

Clostridium difficile was isolated from 14/135 (10.3\%) samples from 8/15 (53.3\%) horses on 6/10 (60\%) farms. Between zero and three/nine (33\%) sites were positive per horse, and multiple sites were positive in four $(27 \%)$ horses (Table 2). Isolates were recovered from the duodenum $(n=1 / 15,6.7 \%)$, jejunum $(n=1 / 15,6.7 \%)$, ileum
( $\mathrm{n}=1 / 15,6.7 \%)$, right dorsal colon $(\mathrm{n}=4 / 15,27 \%)$, small colon $(\mathrm{n}=2 / 15,13.3 \%)$, and rectum/faeces $(\mathrm{n}=5 / 15$, 33\%). In three horses (38\%) C. difficile was isolated from a proximal site but the rectal samples were negative, while in $3(38 \%)$ other horses the rectum and a proximal site were positive and in $2(25 \%)$ horses the rectum was the only positive site. The relative sensitivity of faecal sample culture to detect overall $C$ : difficile presence in a horse was 63\% (CI 95\%:0.29 and 0.89). Agreement between rectal and proximal samples (all proximal sites combined) was good (kappa $=0.61$, standard error 0.19)

\section{Clostridium difficile toxin detection and ribotyping results}

All isolates possessed genes encoding for toxins A and B (Table 2). Five isolates were ribotype 078 and also possessed the gene encoding for part of the binary toxin $(c d t B)$. Four isolates were ribotype 001 and were $c d t B$ negative. The remaining five isolates corresponded to three ribotype profiles not previously identified in this laboratory. These five isolates were $t c d A$ and $t c d B$ positive, but were $c d t B$ negative. Interestingly, more than one ribotype was found in all horses from which multiple compartments were positive.

\section{Prevalence and characterization of C. perfringens}

Clostridium perfringens was only isolated from the left ventral colon of one horse. The detection limit of the method used was low at $9 \mathrm{cfu} / \mathrm{g}$ (data not shown). The single isolate contained only the alpha toxin gene, classifying it as $C$. perfringens type A.

Table 2 Ribotypes and toxin gene profiles of Clostridium difficile isolated from gastrointestinal compartments of healthy horses

\begin{tabular}{|c|c|c|c|c|c|c|}
\hline Horse & Farm & Compartment & Toxin A & Toxin B & CDT & Ribotype $^{1}$ \\
\hline 1 & A & Rectum & + & + & + & 078 \\
\hline \multirow[t]{2}{*}{4} & C & Right Dorsal Colon & + & + & - & 001 \\
\hline & & Rectum & + & + & + & 078 \\
\hline \multirow[t]{2}{*}{5} & D & Right Dorsal Colon & + & + & - & 001 \\
\hline & & Rectum & + & + & + & 078 \\
\hline \multirow[t]{3}{*}{7} & C & Duodenum & + & + & + & 078 \\
\hline & & Right Dorsal Colon & + & + & - & 001 \\
\hline & & Rectum & + & + & + & 078 \\
\hline 10 & C & Small colon & + & + & - & 001 \\
\hline \multirow[t]{3}{*}{11} & $\mathrm{~F}$ & Jejunum & + & + & - & AS2 \\
\hline & & lleum & + & + & - & AS1 \\
\hline & & Right Dorsal Colon & + & + & - & AS1 \\
\hline 12 & G & Rectum & + & + & - & AS1 \\
\hline 15 & J & Small colon & + & + & - & AS3 \\
\hline
\end{tabular}

${ }_{1}^{1}$ PHLS Anaerobic Reference Unit (Cardiff, UK) when appropriate, otherwise, internal nomenclature was used. 


\section{Discussion}

This study showed that $C$. difficile can be isolated from a variety of gastrointestinal compartments of healthy horses and that several distinct ribotypes may be isolated from the same horse. Explanations for the different ribotypes in the same horse include simultaneous transient passage of multiple strains through the gastrointestinal system or colonization of different compartments by diverse strains. Regardless, these data indicate that the typical practice of selecting one colony for typing, an almost universal procedure in studies that have reported C. difficile types in horses $[23,24]$, might underestimate the true ribotype diversity and distribution. Human studies have reported co-existence of different ribotypes in faecal specimens from healthy humans and those affected with CDI $[25,26]$; however, the presence of multiple strains is rarely reported. In a study of healthy humans, Kato and co-workers (2001) reported that only 1/94 (1.1\%) faecal samples positive for $C$. difficile contained more than one ribotype per sample. Similar data have not been available for horses, but this study suggests that methods able to detect different ribotypes in a single sample might be required to get a true understanding of the ribotype distribution in equine samples. Regardless, the potential presence of multiple $C$. difficile strains in the same animal must be considered when designing and interpreting studies.

Clostridium difficile was found in various locations throughout the intestinal tract, which is not surprising given its association with both small and large intestinal disease. As with any study of the intestinal microbiota, it is impossible to definitively state that $C$. difficile was truly colonizing these locations as opposed to passing through transiently following ingestion. This study cannot differentiate between these two, but demonstrates that this organism is adapted to survive and perhaps proliferate in various intestinal locations. Further investigations into the dynamics of $C$. difficile and ways to differentiate transient passage from colonization are required.

Inconsistent detection of $C$. difficile in different intestinal compartments of the same horse could be due to non-homogenous distribution of $C$. difficile in truly colonized animals, intestinal site predilections for $C$. difficile (or specific strains), or presence of $C$. difficile below detection thresholds at some sites.

Overall the prevalence of $C$. difficile in the gastrointestinal tract of horses found in this study (53\%) was higher compared to other studies (typically $0-10 \%$ ), including those performed in the same geographical region [5,7-9]; however, prevalence data should be interpreted with caution, as the study was not designed to determine population prevalence. Also, the presence of multiple animals per farm may have introduced a clustering effect. Six horses in this study originated from one farm, and $C$. difficile was isolated from 3/6 (50\%) of them, potentially slightly over estimating overall prevalence data. Given the small sample size and potential for clustering in one farm, this study should not be taken as a population prevalence study, but rather as a comparison among intestinal compartments and assessment of ribotype distribution. The detection of $C$. difficile in feces of healthy horses shows that horses are exposed to this pathogen frequently, however only a small subset of horses eventually develop disease. Better understanding of the epidemiology of this pathogen is required to better prevent and treat disease.

Assessment of faecal samples is the standard practice for diagnosis of disease caused by enteropathogens, because of the ease of access and the impractical nature of sampling other intestinal compartments in most cases. Therefore, understanding how faecal samples reflect proximal compartments is critical for interpretation of the data. Agreement between rectal samples and proximal compartment was good $(\kappa=0.61)$, although these data do indicate that rectal samples might not absolutely reflect the status of proximal compartments, both in the presence or absence of $C$. difficile and the ribotypes that are recovered. These findings should be considered when interpreting results from other studies, as prevalence of $C$. difficile in the gastrointestinal tract of horses might be higher than faecal prevalence would suggest.

The presence of a variety of ribotypes in this study is not surprising. Previous studies have reported a wide diversity of ribotypes in horses $[24,27]$. The most common ribotype in this study was ribotype 078, commonly found in pigs and cattle [28], and increasingly implicated in community-associated CDI in humans [29,30]. While ribotype 078 has been found in horses $[9,23,28]$, the prevalence here is higher compared to previous studies of horses in this region, such as a 2006-2007 surveillance study where ribotype 078 only accounted for $3 / 52$ (5.8\%) of isolates from healthy horses [9]. This could indicate that this ribotype is emerging in this region. The second most common strain in this study was ribotype 001. This ribotype has been previously reported in horses $[9,27]$ and is also a predominant human clone, being the most common ribotype in a study of people in hospitals in the region [31]. Overall, nine of the 14. (64\%) isolates found in this study were types that have been implicated in CDI in humans in the region [31]. Data such as these raise concern that $C$. difficile may be a zoonotic pathogen [32]; however, proof of interspecies transmission is currently lacking.

The low prevalence of C. perfringens in intestinal content samples obtained in this study is consistent with previous studies. While $C$. perfringens is commonly found in horses with enteric disease, foals and pregnant 
mares, the low prevalence reported here is consistent with other studies of adult horses [13,16]. Methodological issues should always be considered with studies reporting low prevalence. Standard and validated methods are not available for $C$. perfringens isolation from equine faeces; however, the method used here had a detection threshold of $9 \mathrm{cfu} / \mathrm{ml}$ of faeces (data not presented) and identical protocols were used in a study that identified C. perfringens shedding in $88 \%$ of healthy dogs [33]. Thus, it is unlikely that poor test sensitivity accounted for the low prevalence reported here, and these results suggest that $C$. perfringens is uncommonly shed by healthy horses, or shed intermittently or at very low levels. Whether the higher isolation rates from horses with gastrointestinal tract disease indicates cause or simply opportunistic overgrowth of this organism is still unclear $[13,15]$.

A limitation of this study was its small sample size and therefore care has to be taken when interpreting these results; however, this is the first study determining the prevalence and ribotype distribution of $C$. difficile in different compartments of healthy horses and despite the small sample size it gives new insight into the epidemiology of this pathogen.

Information on antimicrobial use in the weeks prior to euthanasia was not available; however, none of the horses had any clinical condition reported that would likely have been treated with parenteral antimicrobials. It is certainly plausible that prior antimicrobial use would have affected results of this study; however, any effect would probably have been on overall prevalence, not an alteration of distribution of $C$. difficile in different intestinal locations. If there were any impact on C. perfringens, it would have been expected to increase the prevalence, something that was not observed here given the very low prevalence.

\section{Conclusions}

This study provides new epidemiologic data on the presence and distribution of $C$. difficile and $C$. perfringens throughout the intestinal tract of healthy horses. While faecal samples provide a reasonable indication of the presence or absence of these organisms in the proximal intestinal tract, differences in $C$. difficile distribution and types can be found in different intestinal locations, something that must be considered when designing and interpreting studies relying on faecal sample collection alone. While the gastrointestinal microbiota of the horse remains a poorly understood, complex and important polymicrobial environment, a better understanding of important organisms such as $C$. difficile and C. perfringens may help to elucidate the epidemiology and microbiology of the intestinal microbiota in health and disease.

\section{Endnotes}

${ }^{\mathrm{a}}$ Oxoid, Nepean Canada.

${ }^{\mathrm{b}}$ ProDisc test; Remel, Carr-Scarborough Microbiologicals, Inc, Decatur, GA, USA.

${ }^{\mathrm{C} I n s t a G e n e ~ M a t r i x ; ~ B i o-R a d, ~ M i s s i s s a u g a, ~ O n t a r i o, ~ C a n a d a . ~}$ ${ }^{\mathrm{d} O x o i d, ~ N e p e a n, ~ C a n a d a . ~}$

\section{Abbreviations}

BHI: Brain heart infusion broth; CAMP: Christie-Atkins-Munch -Peterson testing; CDI: Clostridium difficile infection; CDMN: C. difficile moxalactam and norfloxacin broth; CDT: Binary Toxin of Clostridium difficile; DNA: Desoxyribonucleic acid; PCR: Polymerase chain reaction.

\section{Competing interests}

The authors declare that they have no competing interests.

\section{Authors' contribution}

AS was involved in study design, carried out the sample collection, laboratory work and drafted the manuscript. JW conceived the study and was part of the study design and helped with laboratory analysis. LA participated in the design of the study and interpretation of data. HS and participated in its design and coordination and helped to draft the manuscript. PS was involved in study design, coordination and drafting of the manuscript. All authors read and approved the final manuscript.

\section{Acknowledgements}

The authors thank William Sears for his help with statistical analysis. Sources of funding: Equine Guelph

\section{Author details}

${ }^{1}$ Department of Clinical Studies, Ontario Veterinary College, University of Guelph, Guelph, Canada. ${ }^{2}$ Department of Pathobiology, Ontario Veterinary College, University of Guelph, Guelph, Canada. ${ }^{3}$ Department of Veterinary Disease Biology, University of Copenhagen, Copenhagen, Denmark.

Received: 19 March 2012 Accepted: 19 June 2012

Published: 29 June 2012

\section{References}

1. Song X, Bartlett JG, Speck K, Naegeli A, Carroll K, Perl TM: Rising economic impact of clostridium difficile-associated disease in adult hospitalized patient population. Infect Control Hosp Epidemiol 2008, 29(9):823-828.

2. Keel MK, Songer JG: The comparative pathology of Clostridium difficileassociated disease. Vet Pathol 2006, 43(3):225-240.

3. Arroyo LG, Weese JS, Staempfli HR: Experimental Clostridium difficile enterocolitis in foals. J Vet Intern Med 2004, 18(5):734-738.

4. Baverud V, Gustafsson A, Franklin A, Lindholm A, Gunnarsson A: Clostridium difficile associated with acute colitis in mature horses treated with antibiotics. Equine Vet J 1997, 29(4):279-284.

5. Weese JS, Staempfli HR, Prescott JF: A prospective study of the roles of clostridium difficile and enterotoxigenic Clostridium perfringens in equine diarrhoea. Equine Vet J 2001, 33(4):403-409.

6. Weese JS, Toxopeus L, Arroyo L: Clostridium difficile associated diarrhoea in horses within the community: predictors, clinical presentation and outcome. Equine Vet J 2006, 38(2):185-188.

7. Baverud V, Gustafsson A, Franklin A, Aspan A, Gunnarsson A: Clostridium difficile: prevalence in horses and environment, and antimicrobial susceptibility. Equine Vet J 2003, 35(5):465-471.

8. McNamara SE, Abdujamilova N, Somsel P, Gordoncillo MJ, Dedecker JM, Bartlett PC: Carriage of Clostridium difficile and Other Enteric Pathogens Among a 4-H Avocational Cohort. Zoonoses Public Health 2010, 58(3):192-199.

9. Medina-Torres CE, Weese JS, Staempfli HR: Prevalence of Clostridium difficile in horses. Vet Microbiol 2011, 152(1-2):212-215.

10. Lavallee C, Laufer B, Pepin J, Mitchell A, Dube S, Labbe AC: Fatal Clostridium difficile enteritis caused by the BI/NAP1/027 strain: a case series of ileal C. difficile infections. Clin Microbiol Infect 2009, 15(12):1093-1099.

11. Arroyo LG, Stampfli HR, Weese JS: Potential role of Clostridium difficile as a cause of duodenitis-proximal jejunitis in horses. J Med Microbio/ 2006, 55(Pt 5):605-608. 
12. Songer JG: Clostridial enteric diseases of domestic animals. Clin Microbio/ Rev 1996, 9(2):216-234

13. Waggett BE, MCGorum BC, Wernery U, Shaw DJ, Pirie RS: Prevalence of Clostridium perfringens in faeces and ileal contents from grass sickness affected horses: comparisons with 3 control populations. Equine Vet $J$ 2010, 42(6):494-499.

14. Tschirdewahn B, Notermans S, Wernars K, Untermann F: The presence of enterotoxigenic Clostridium perfringens strains in faeces of various animals. Int J Food Microbiol 1991, 14(2):175-178.

15. Herholz C, Miserez R, Nicolet J, Frey J, Popoff M, Gibert M, Gerber H, Straub $R$ : Prevalence of beta2-toxigenic Clostridium perfringens in horses with intestinal disorders. J Clin Microbiol 1999, 37(2):358-361.

16. Tillotson K, Traub-Dargatz JL, Dickinson CE, Ellis RP, Morley PS, Hyatt DR, Magnuson RJ, Riddle WT, Bolte D, Salman MD: Population-based study of fecal shedding of Clostridium perfringens in broodmares and foals. J Am Vet Med Assoc 2002, 220(3):342-348.

17. Bacciarini LN, Boerlin P, Straub R, Frey J, Grone A: Immunohistochemical localization of Clostridium perfringens beta2-toxin in the gastrointestinal tract of horses. Vet Pathol 2003, 40(4):376-381.

18. Bidet $P$, Barbut F, Lalande $V$, Burghoffer B, Petit JC: Development of a new PCR-ribotyping method for Clostridium difficile based on ribosomal RNA gene sequencing. FEMS Microbiol Lett 1999, 175(2):261-266.

19. Kato $H$, Kato N, Watanabe K, Iwai N, Nakamura H, Yamamoto T, Suzuki K, Kim SM, Chong Y, Wasito EB: Identification of toxin A-negative, toxin Bpositive Clostridium difficile by PCR. J Clin Microbiol 1998, 36(8):2178-2182.

20. Stubbs S, Rupnik M, Gibert M, Brazier J, Duerden B, Popoff M: Production of actin-specific ADP-ribosyltransferase (binary toxin) by strains of Clostridium difficile. FEMS Microbiol Lett 2000, 186(2):307-312.

21. Baums CG, Schotte U, Amtsberg G, Goethe R: Diagnostic multiplex PCR for toxin genotyping of Clostridium perfringens isolates. Vet Microbiol 2004, 100(1-2):11-16.

22. Landis JR, Koch GG: The measurement of observer agreement for categorical data. Biometrics 1977, 33(1):159-174.

23. Arroyo LG, Staempfli H, Weese JS: Molecular analysis of Clostridium difficile isolates recovered from horses with diarrhea. Vet Microbiol 2007 120(1-2):179-183.

24. Ossiprandi MC, Buttrini M, Bottarelli E, Zerbini L: Preliminary molecular analysis of Clostridium difficile isolates from healthy horses in northern Italy. Comp Immunol Microbiol Infect Dis 2010, 33(6):e25-e29.

25. Kato H, Kita H, Karasawa T, Maegawa T, Koino Y, Takakuwa H, Saikai T, Kobayashi K, Yamagishi T, Nakamura S: Colonisation and transmission of Clostridium difficile in healthy individuals examined by PCR ribotyping and pulsed-field gel electrophoresis. J Med Microbiol 2001, 50(8):720-727.

26. van den Berg RJ, Ameen HA, Furusawa T, Claas EC, van der Vorm ER, Kuijper EJ: Coexistence of multiple PCR-ribotype strains of Clostridium difficile in faecal samples limits epidemiological studies. J Med Microbiol 2005, 54(Pt 2):173-179.

27. Arroyo LG, Kruth SA, Willey BM, Staempfli HR, Low DE, Weese JS: PCR ribotyping of Clostridium difficile isolates originating from human and animal sources. J Med Microbiol 2005, 54(Pt 2):163-166.

28. Keel K, Brazier JS, Post KW, Weese S, Songer JG: Prevalence of PCR ribotypes among Clostridium difficile isolates from pigs, calves, and other species. J Clin Microbio/ 2007, 45(6):1963-1964.

29. Goorhuis A, Bakker D, Corver J, Debast SB, Harmanus C, Notermans DW, Bergwerff AA, Dekker FW, Kuijper EJ: Emergence of Clostridium difficile infection due to a new hypervirulent strain, polymerase chain reaction ribotype 078. Clin Infect Dis 2008, 47(9):1162-1170.

30. Mulvey MR, Boyd DA, Gravel D, Hutchinson J, Kelly S, McGeer A, Moore D, Simor A, Suh KN, Taylor G, Weese JS, Miller M: Canadian Nosocomial Infection Surveillance Program: Hypervirulent Clostridium difficile strains in hospitalized patients, Canada. Emerg Infect Dis 2010, 16(4):678-681.

31. Martin H, Willey B, Low DE, Staempfli HR, McGeer A, Boerlin P, Mulvey M, Weese JS: Characterization of Clostridium difficile strains isolated from patients in Ontario, Canada, from 2004 to 2006. J Clin Microbiol 2008, 46(9):2999-3004

32. Gould LH, Limbago B: Clostridium difficile in food and domestic animals: a new foodborne pathogen? Clin Infect Dis 2010, 51(5):577-582.

33. Marks SL, Kather EJ, Kass PH, Melli AC: Genotypic and phenotypic characterization of Clostridium perfringens and Clostridium difficile in diarrheic and healthy dogs. J Vet Intern Med 2002, 16(5):533-540. doi:10.1186/1746-6148-8-94

Cite this article as: Schoster et al:: Presence and molecular characterization of Clostridium difficile and Clostridium perfringens in intestinal compartments of healthy horses. BMC Veterinary Research 2012 8:94.

\section{Submit your next manuscript to BioMed Central and take full advantage of:}

- Convenient online submission

- Thorough peer review

- No space constraints or color figure charges

- Immediate publication on acceptance

- Inclusion in PubMed, CAS, Scopus and Google Scholar

- Research which is freely available for redistribution 